\title{
Applying continuous functional traits to large brown macroalgae: variation across tidal emersion and wave exposure gradients
}

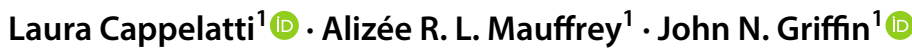

Received: 14 March 2019 / Accepted: 3 July 2019 / Published online: 10 October 2019

(c) The Author(s) 2019

\begin{abstract}
Ecologists use a functional trait-based approach to seek a general understanding of organism-environment interactions, but, among primary producers, the empirical basis rests on vascular plants. We hypothesised that with increasing intertidal elevation, traits of large brown macroalgae would reflect a resource acquisition vs. conservation (stress tolerance) trade-off at species and community levels. Across the elevation gradient at four UK sites of varying wave exposure, we: (1) screened species' relevant morphological traits, using principal component analysis to reduce dimensionality; and (2) up-scaled species' traits using community weighted trait means (CWMs). The first principal component (PC1) strongly related to specific thallus area and thallus dry matter content, representing an acquisition-conservation trade-off. Although species generally shifted to the conservative end of this axis as elevation increased, mid-shore Ascophyllum nodosum sat at the extreme conservative end. PC2 related to holdfast ratio, thickness and length, with A. nodosum scoring higher than other mid-shore species. CWMs of PC1 decreased with elevation at two sites indicating a shift from 'fast' to 'slow' ecosystem functioning, but this relationship was disrupted by A. nodosum at the sheltered site, and by the up-shore extent of Laminaria digitata at the most exposed site. The anomalous traits of A. nodosum reflect its unique competitive strategy (slow, persistent growth) in the relatively stressful mid-shore. Seaweed functional traits show promise in linking species' identities to their strategies and ecosystem contributions. However, because resource conservation traits can be related to competitive as well as stresstolerance strategies, predicting seaweed trait responses to environmental stress gradients is challenging.
\end{abstract}

\section{Introduction}

Characterising how organisms' functional traits vary along environmental gradients can reveal species' ecological strategies (Cornwell and Ackerly 2009), the extent of intraspecific variability (Fajardo and Piper 2011), and the adaptive significance of traits (Kraft et al. 2007). Doing so also elucidates how the environment affects trait values at the community level, and therefore the consequences of spatial and

Responsible Editor: K. Bischof.

Reviewed by F. Arenas, A. Foggo, Ch. Hepburn.

Electronic supplementary material The online version of this article (https://doi.org/10.1007/s00227-019-3574-5) contains supplementary material, which is available to authorized users.

Laura Cappelatti

lauracappelatti@gmail.com

1 Biosciences Department, Swansea University, Wallace Building, SA28PP Swansea, Wales, UK temporal variation in the environment for ecosystem functioning (Suding et al. 2008). However, modern functional ecology, a science based on multiple continuous traits measured at the level of individuals, has largely been focused on vascular plants (e.g., Bloomfield et al. 2018) and rarely applied to other, evolutionarily distant, groups of primary producers such as macroalgae or seaweeds.

Here, we adopt approaches of functional ecology to study 'large brown macroalgae' (LBM), a seaweed group including kelps and rockweeds, that dominate standing biomass along temperate rocky intertidal and shallow subtidal zones worldwide (Dayton 1985). These foundation species are major contributors to near-shore primary productivity, and support diverse ecosystem services including fisheries, coastal protection, and carbon storage (e.g., Smale et al. 2013). Classic studies in the rocky intertidal point towards functional differences between species of LBM and show the effects of environmental gradients-especially tidal emersion period (represented height on the shore) and wave exposure (commonly represented by wave fetch)—on their distribution (Southward 1959; Ballantine 1961). Furthermore, 
recent work illustrates how these factors affect the morphology and fitness of individual species (Hepburn et al. 2007). However, categorisation of species into coarse functional groups remains the usual approach in macroalgal ecology (Steneck and Dethier 1994; Arenas et al. 2016; Gómez and Huovinen 2011), and assemblages of LBM have not previously been investigated using a range of continuous functional traits. Therefore, fundamental questions such as the extent to which gradients including shore height and wave exposure are associated with functional traits at individual, species, and community levels have remained unexplored.

Like vascular plants, LBM are sedentary, multicellular, and differentiated photosynthesising organisms (Hurd et al. 2014). Accordingly, we expect the functional ecology of vascular plants to inform macroalgal functional ecology. Plant ecological strategies range from resource conservative, stress-tolerant, and long-lived-so-called "slow" speciesto resource acquisitive, competitive, and short-lived- "fast" species (Grime 1974, Reich 2014). This spectrum reflects the inevitable trade-off between traits that are advantageous in resource-rich environments (e.g., rapid rates of resource acquisition and loss and high rates of tissue turnover), and the more conservative strategy prevailing in resource-poor or stressful environments (Díaz et al. 2004). For LBM in the intertidal, tidal emersion represents a gradient where these shifts in functional traits should be visible. A stress tolerant, resource-conservative strategy (e.g., low specific thallus ['leaf'] area) should be beneficial at the upper shore, where exposure to air for long periods leads to desiccation and slows photosynthesis (Chapman 1995). Meanwhile, a resource acquisitive strategy (e.g., high specific thallus area) should prevail on the more light-competitive lower shore (Littler and Littler 1980). Following plant ecology, we expect strategies and associated trade-offs to manifest as coordinated changes across functional traits (Díaz et al. 2004). Across shore locations, however, gradients of wave exposure, known to be associated with changes in community structure (Ballantine 1961; Burrows et al. 2008) and individual traits (Cousens 1982; Bäck 1993; Blanchette 1997), may disrupt associations between species' and community-level trait values and tidal emersion. Finally, variability within species threatens to undermine application of traits at the species level. Although plant ecologists have addressed its contribution in many systems (Siefert et al. 2015), how intraspecific compares to interspecific variation in trait space is still not known for macroalgae.

Here, we evaluate variability in the functional traits of LBM across gradients of shore height and wave exposure. We conducted surveys and screened individuals for functional traits related to the resource acquisition-stresstolerance trade-offs, along the intertidal at four sites of varying wave exposure in south Wales (UK). Specifically, we investigated: (1) how species of LBM that span shore heights differ in their position in functional trait space; (2) how this interspecific variability scales to the community level along shore heights at sites of varying wave exposure; and (3) given expected intraspecific variability, the extent to which species maintain functional differences across a wave exposure gradient. We hypothesised that, across shore heights, species traits will reflect adaptations to the emersion period in an overall more conservative, stress tolerant, strategy. Although we examined the robustness of these relationships across sites of varying wave exposure, our main focus was on shore height. Table 1 outlines our predictions for how traits would change with shore height and the mechanisms underlying this variation.

\section{Methods}

\section{Study sites}

The study was conducted on four rocky shores in south Wales (UK), during the summers of 2017 and 2018. Shores in this region experience large tidal ranges, and typically host stands of LBM characteristic of northeastern Atlantic rocky shores. We selected accessible sites covering a wide range of wave exposures and with extensive carboniferous limestone intertidal platforms. Three of the sites span ca. $20 \mathrm{~km}$ of the Gower Peninsula (tidal range of $10.37 \mathrm{~m}$ ): Rhossili (exposed; 51.56N, 4.32W), Bracelet Bay (semiexposed; $51.57 \mathrm{~N}, 3.98 \mathrm{~W}$ ), and Oxwich (sheltered; $51.55 \mathrm{~N}$, $4.15 \mathrm{~W}$ ). Since very sheltered sites could not be found on the Gower, we selected an additional site ca. $50 \mathrm{~km}$ west, located in a ria (Milford Haven, Pembrokeshire, tidal range of $7.89 \mathrm{~m})$ : Angle Bay $(51.68 \mathrm{~N}, 5.08 \mathrm{~W})$. As an index of wave exposure, we calculated the average wave fetch for each site, which provides good explanatory power for UK rocky shore communities (Burrows et al. 2008, Burrows 2012). We used the $\mathrm{R}$ packages (R Core Team 2018) rgdal (Bivand et al. 2018), to get the spatial points, and fetchR (Seers 2017), to obtain the fetch distances of nine directions, to a maximum distance of $300 \mathrm{~km}$, as default. Average fetch values were $1.95 \mathrm{~km}$ at Angle Bay, $16.43 \mathrm{~km}$ at Oxwich, $24.79 \mathrm{~km}$ at Bracelet Bay, and $67.17 \mathrm{~km}$ at Rhossili. We also conducted rapid assessments of water parameters (salinity, temperature, and nutrient levels) and found minimal differences between sites (see Appendix S1 and Table S1 in Supplementary material for details). Accordingly, and in line with a long history of phycological studies (Ballantine 1961; Hepburn et al. 2007), we expected wave exposure to be a key driver of any trait differences between sites. 
Table 1 Functional traits measured, their functional relevance, expected variation along the gradient of shore height, and the mechanisms that explain them

\begin{tabular}{|c|c|c|c|c|c|}
\hline \multirow[t]{2}{*}{ Trait } & \multirow[t]{2}{*}{ Plant analogue } & \multirow[t]{2}{*}{ Part } & \multirow[t]{2}{*}{ Function and ref. } & \multicolumn{2}{|l|}{ Shore height $\nearrow$} \\
\hline & & & & Trait response & Mechanism \\
\hline Specific thallus area (STA) & Specific leaf area & Blade & Light capture ("fast") a & $\swarrow$ & Slows water loss \\
\hline Thickness & Leaf thickness & Blade & Physical structure ("slow") & $\nearrow$ & Slows water loss \\
\hline $\begin{array}{l}\text { Surface area: volume ratio } \\
\text { (SAV) }\end{array}$ & Leaf SAV & Whole & Nutrient capture ("fast") ${ }^{\mathrm{c}}$ & $\swarrow$ & Slows water loss \\
\hline $\begin{array}{l}\text { Thallus dry matter content } \\
\text { (TDMC) }\end{array}$ & Dry matter content (DMC) & Whole & Physical structure ("slow") & $\nearrow$ & $\begin{array}{l}\text { Increases tolerance to } \\
\text { desiccation }\end{array}$ \\
\hline Total length & Total length/height & Whole & $\begin{array}{l}\text { Competition for light } \\
\text { ("fast") }\end{array}$ & $\swarrow$ & $\begin{array}{l}\text { Economic: reduced } \\
\text { requirement to compete } \\
\text { for light }\end{array}$ \\
\hline Holdfast ratio & Root: shoot ratio & Whole & $\begin{array}{l}\text { Anchoring to substrate } \\
\text { ("slow") }\end{array}$ & $\swarrow$ & $\begin{array}{l}\text { Economic: reduced } \\
\text { requirement for strong } \\
\text { attachment }\end{array}$ \\
\hline
\end{tabular}

Arrows indicate whether trait values are expected to increase or decrease. "Part" refers to the part of the macroalgae used to measure the trait in this study. "Mechanism" refers to the hypothesised mechanism through which the trait response (rather than the trait itself) is associated with the environmental driver. "Slow" or "fast" indicates the association between the trait and the rate of physiological and ecological processes (see, e.g., Reich 2014). Example references supporting each function and shown in superscript letters are: ${ }^{a}$ Wilson et al. (1999), 'Markager and SandJensen (1996), 'Littler (1980), ${ }^{\mathrm{d}}$ Hodgson et al. (1999), and "Sjøtun and Fredriksen (1995). See "Methods" for explanation of traits and hypothesised responses

\section{Sampling for traits}

We assessed morphological traits of LBM at the individual level (within species). Across the intertidal and during low tide, at each site, we haphazardly positioned nine replicate $1 \times 1 \mathrm{~m}$ quadrats, at least $5 \mathrm{~m}$ apart (spread equally among the lower, middle and upper parts of the shore), providing 36 quadrats in total. Individuals were sampled from each replicate quadrat. Due to the effort necessary to measure traits at this scale, we collected a maximum of three samples per species, per quadrat, adding to a total of $n=167$ individuals. Samples were stored in bags with seawater, and kept in coolers until returning to the laboratory, where they were immediately transferred to a freezer $\left(-18{ }^{\circ} \mathrm{C}\right)$. Sampling took place in summer 2017 (June and July).

\section{Survey of LBM communities}

To fully capture the dominant species of intertidal LBM and the assemblages that they form in the study region, we went back to survey the study sites in the summer of 2018 (July-August). A thorough census allowed us to scale traits to the community level and observe how they change with the environmental gradients (shore height and wave exposure). Along four transects at each shore, spanning the whole intertidal zone, we placed $1 \times 1 \mathrm{~m}$ quadrats every $10 \mathrm{~m}$. This also allowed us to accurately quantify the mean shore height distribution of each LBM species for the species-level analyses. Abundance was estimated by counting how many of the 25 string squares inside the quadrat were covered, and then transforming that into percentage values (Dethier et al. 1993). Since the study species share similar gross morphologies, cover provides an appropriate, as well as quick, assessment of abundance (Edmunds and Carpenter 2001, Aquilino et al. 2009).

\section{Shore height}

The position of each quadrat for both surveys was marked using GPS (Garmin 62 ST, Garmin Ltd., Olathe, KS, US) and its height (above chart datum) ascertained using publicly available LIDAR data (lle.gov.wales). To account for differences in tidal range among sites, so they are comparable, we used 'relative height' $(\mathrm{RH})$ as a measure of the shore height of replicate quadrats, calculated as:

$\mathrm{RH}=(\mathrm{HQ}-\mathrm{LAT}) / \mathrm{TTR}$,

where HQ is the height of the quadrat, LAT is the lowest astronomical tidal height of the specific shore, and TTR is the total tidal range of the region (www.ntslf.org). The range of RH spanning the sampled transects varied among sites: Angle bay: 0.22-0.70; Oxwich: 0.07-0.78; Bracelet Bay: $0.07-0.75$; and Rhossili: $0.15-0.73$, possibly owing to differences in exposure, aspect, or shore topography.

\section{Trait measurements}

We assessed six morphological traits that were either known or expected to relate to the ability of individual LBM to cope with environmental stressors of shore height (tidal emersion) 
and wave exposure (see Table 1 for rationale and supporting references). Most of these traits have been measured previously in macroalgae, although not systematically, and have analogue traits that are routinely measured in terrestrial plant ecology (Cornelissen et al. 2003). To allow efficient screening across individuals, the functional traits served as indicators of physiological or physical functions, rather than being direct measurements of them, i.e., 'functional markers' (sensu Garnier et al. 2004). Before trait measurement, samples were thawed and cleaned from epibiota, and large fucoid individuals with many fronds were cut by half, longitudinally. Traits were considered at the whole individual or blade-only level (Table 1) and are described below.

The first three traits (1-3) were specific thallus area (STA), surface area-to-volume ratio (SAV), and thallus thickness. (1) STA and (2) SAV, similarly to specific leaf area (SLA) in plants, capture the ratio between photosynthetically active surface tissues and structural compounds (Wilson et al. 1999). These traits are expected to be related to (3) thallus thickness, because at constant density, a thicker thallus (or leaf) will decrease surface area-to-mass or volume ratios (Reich et al. 1999). High values of STA or SAV are associated with higher productivity (Rodriguez et al. 2016; Sakanishi et al. 2017) and nutrient uptake (Hein et al. 1995), but favor water loss and are associated with a weaker physical structure (Littler 1980). Meanwhile, thicker thalli provide structural strength, conferring resistance to frond breakage in wave-exposed conditions (e.g., Wing et al. 2007), but are associated with reduced productivity (Markager and Sand-Jensen 1996) and increase in drag forces. We measured surface area (SA) with software ImageJ (Schneider et al. 2012) from images of samples, cut into thallus parts, and spread on an A1 light pad (MiniSun, Manchester, UK). STA was calculated by dividing the blade SA by its dry mass and is expressed as $\mathrm{cm}^{2} \mathrm{~g}^{-1}$. SAV (given as $\mathrm{cm}^{2} \mathrm{~mL}^{-1}$ ) was obtained from dividing whole SA by total volume, which was measured through water displacement in a graduated cylinder $(0.1 \mathrm{~mL}$ resolution). For large individuals such as kelp, we used a larger cylinder with $1 \mathrm{~mL}$ resolution. Thickness is given in $\mathrm{cm}$ and was averaged from ten measurements along the blades, using a digital thickness gauge with $0.001 \mathrm{~mm}$ precision (Digital Micrometers Ltd., Sheffield, UK).

Three further traits were included: (4) total length, (5) holdfast ratio, and (6) thallus dry matter content (TDMC). Total length should determine an individual's position in the water column, influencing light availability to the thallus (Littler and Littler 1980) and, analogously to plant height (Hodgson et al. 1999), relate to competitive dominance. Total length is the maximum length of the whole individual, and it was measured in centimetres. Holdfast ratio reflects the trade-off macroalgae face between preferentially allocating resources to the fronds to maximise photosynthetic rates and investing in anchoring structures under harsher conditions to prevent dislodgment (Sjøtun and Fredriksen 1995). This trait consists of the ratio of holdfast dry mass to the dry mass of the remaining thallus parts. Dry matter content captures the ratio between structural compounds and waterfilled, nutrient-rich photosynthetically active tissues (Wilson et al. 1999). A high thallus dry matter content (TDMC) should strengthen macroalgae against wave damage and, by reducing the rate of - and tolerance to-water loss, increase desiccation tolerance (Schonbeck and Norton 1979). TDMC was obtained by dividing the dry mass by the fresh mass of the whole individual.

\section{Statistical analyses}

All analyses were performed in R. To explore how LBM species vary in functional trait space, we performed a principal component analysis (PCA) using package ade4 (Dray and Dufour 2007) on the six traits, using scaled, individual values. Prior to the PCA, we log-transformed the traits and visually checked the linearity of trait-trait relationships. A pair of traits was moderately correlated (SAV and STA, $r=0.76$ ), so to make sure that would not influence the outcome of the PCA, we performed the same ordination removing SAV. This had only negligible effects on the species' axes coordinates or the correlation between traits and axes (Appendix S2). Because of human error during sampling, 58 individual trait measures (representing 6\% of all trait values) were absent from our data set. We, therefore, conducted analyses with these missing values imputed using the package mice (van Buuren and Groothuis-Oudshoorn 2011) and this did not appreciably affect species position relative to each other or trait loadings on axes (see Appendix S2, Table S2, Fig. S2).

To evaluate how this interspecific variability scales to the community level along the shore height gradient and across sites, we examined how community weighted means (CWMs) of loadings from PC1 and PC2 varied with RH at each site. CWM uses species means and assigns proportional weight to the traits according to the abundance of each species, therefore making it possible to relate traits to ecosystem functioning, as has been done in plant communities (e.g., Vile et al. 2006). Moreover, because this approach assigns trait values at the species level, it assumes that species identity (rather than site $\mathrm{x}$ species interactions) is the most important source of trait variation. CWMs express the dominant traits in a community (Mokany et al. 2008), so to focus our analyses on communities dominated by LBM, we selected communities where the total cover of these species was of at least one-third (33\% of quadrat area). We used the data from the survey and calculated CWMs for each quadrat using package "FD" (Laliberté et al. 2014). Then, we plotted the CWMs of each axis for all sites individually to observe 
their distribution along the relative heights. Because they were not linear, we used Kendall's rank correlation (which also allows ties) to statistically test the effect of relative heights on traits for each site. We show the data distribution along with pie charts of species' relative abundances on each point to highlight the species that were driving any trends or patterns.

We next evaluated the degree of intraspecific variability across sites of varying wave exposure, and the extent to which species maintain functional trait differences in the face of this variability. We ran a linear mixed model using lme4 in R (Bates et al. 2015), fitting species by site as predictors of PCs 1 and 2. To account for the possible nonindependence of samples collected from the same quadrat, we fitted quadrat identity as a random effect, but this did not improve the model fit (by AIC comparison) and so we report the results of the linear model (ANOVA). Note that we expected the distribution of species to be strongly related to RH due to the obvious zonation, so we did not plan analyses including both species and $\mathrm{RH}$ as simultaneous predictors. However, we did test whether residual variance from the above models could be attributed to RH (Appendix S3, Table S3). To integrate multiple traits, we performed the same species by site model using PERMANOVA based on Euclidian distances using adonis in the package vegan (Oksanen et al. 2018), with the scaled trait scores (Table S4). Two species ( $S$. latissima and H. siliquosa) were removed from these analyses, because they were found at only one site and in less than five quadrats. Of those included, $A$. nodosum and $L$. digitata were both missing from a single site (Oxwich and Angle Bay, respectively); the remaining four species occurred at all four sites.

\section{Results}

We found eight species belonging to three families. The total number of samples for trait measurement was 14 for Ascophyllum nodosum, 27 for Fucus spiralis, 45 for Fucus serratus, 31 for Fucus vesiculosus, 22 for Pelvetia canaliculata (family Fucaceae), 3 for Halidrys siliquosa (family Sargassaceae), 17 for Laminaria digitata, and 8 for Saccharina latissima (family Laminariaceae). Species' mean relative heights and ranges for both surveys are given in Table S5.

\section{The spectrum of functional trait variation}

Across sites and shore heights, PC1 captured $46.1 \%$ and PC2 captured $21.5 \%$ of variation in function trait space (Fig. 1). The traits that most contributed to the first and second axes of variation were STA, SAV, and TDMC (on PC1) and holdfast ratio, blade thickness, and total length (on PC2). PC 3 captured an additional $16.7 \%$ variation and was driven mostly by length and holdfast ratio (Table S2). Despite intraspecific variability and the notable overlapping positions of species in the Fucus genus, most species occupied distinct regions of trait space (Fig. 1; Table 2 (ANOVA), species effect: PC 1 and $2: R^{2}=0.72, p<0.001$ ) and could be associated with traits or axes, illustrating the nature of their functional differences. STA was positively and strongly associated with $S$. latissima, a kelp species found at low shore and restricted to the most sheltered site. Length and holdfast ratio were associated with $L$. digitata, a kelp species of the low shore which is absent from the most sheltered site. TDMC was associated with $P$. canaliculata, the species highest on the shore at all sites. Thickness was associated with the mid-shore species $A$. nodosum, which was distinct from other mid-shore species $F$. vesiculosus and $F$. serratus. Among the LBM, these Fucus species and the upper shore $F$. spiralis shared the most similarity. Trait means and variance for each species are shown in Fig. S1.

We can observe how species differentiate in PCs 1 and 2 with increasing shore height (Fig. 1, bottom panel). In general, species' values on both PC1 and PC2 declined with their average shore height. However, A. nodosum was a clear outlier, occupying the mid-shore while scoring lower on PC1 than high shore species, and scoring similarly to low-shore species on PC2.

\section{Scaling species' differences to the community level}

The relationships between increasing shore height and CWMs based on PC1 and 2 varied across sites (Figs. 2 and 3). PC1 significantly decreased with relative height at the two sites in the middle of the exposure gradient, Bracelet Bay and Oxwich (tau $=-0.72$ and -0.75 , respectively). Accordingly, at these two sites, higher on the shore, dominant species exhibited lower STA and SAV, and higher TDMC. There was also a decrease in PC2 with increasing height at Oxwich ( $\operatorname{tau}=-0.75)$, indicating that at this site, higher on the shore dominant species were shorter, thicker and with a lower holdfast ratio. There were no clear relationships between height and CWMs of PCs at either the very sheltered Angle Bay or the exposed Rhossilli. At Angle, this can be explained by the dominance and relatively low-shore extent of A. nodosum (Figs. 2 and 3), with its anomalous traits (see above). At Rhossili, this can be explained by the up-shore extent of the otherwise lower shore L. digitata.

\section{Intraspecific and interspecific variability across sites of varying wave exposure}

Species' traits and differences in trait space among them varied with site, to some extent. Although there was no clear evidence of a site-species interaction for PC1 $(p=0.07$, Table 2), there was an interaction between site and species 

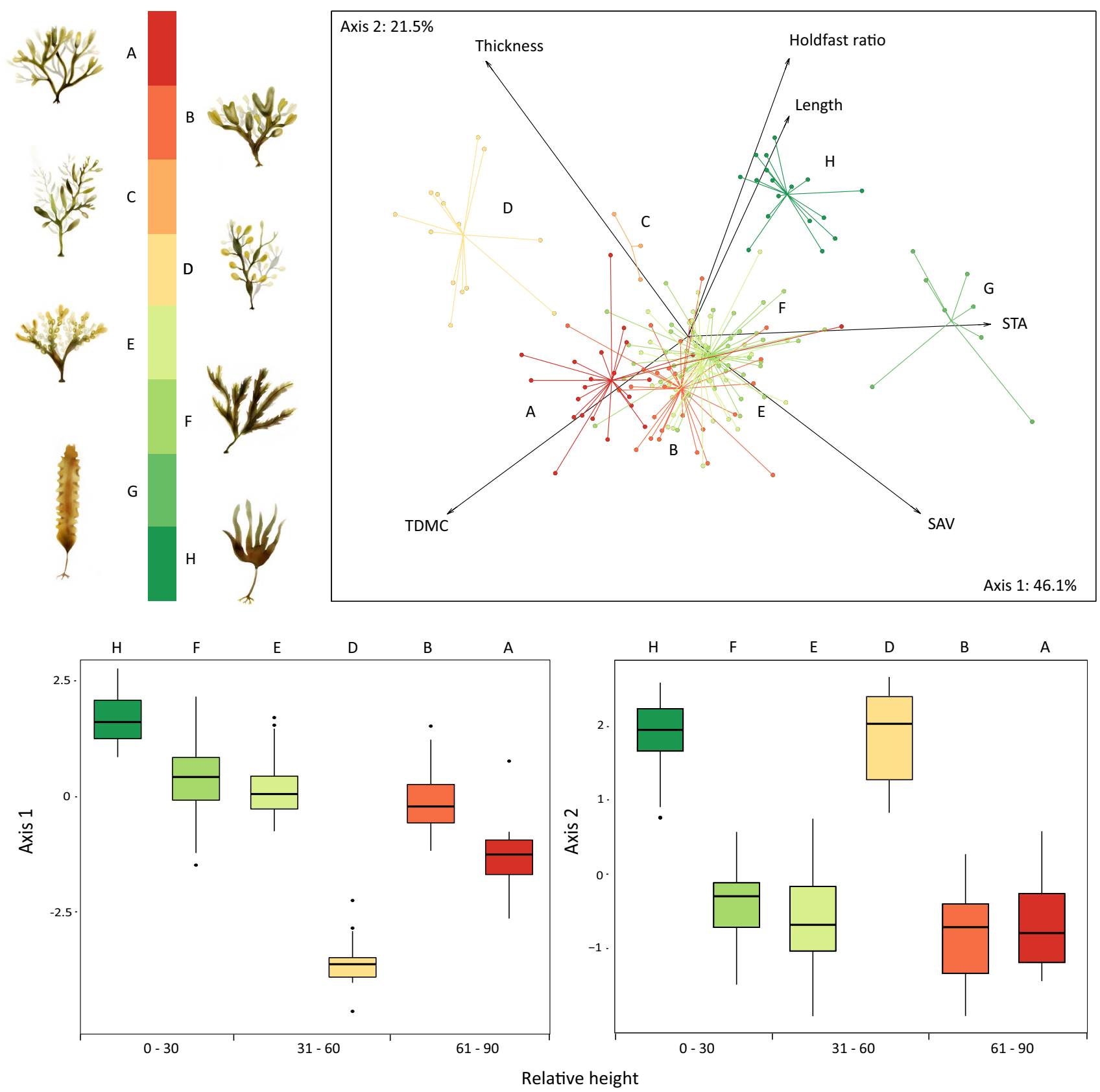

Fig. 1 First two PCA axes of large brown macroalgae, based on trait survey from 2017. The top panel shows the distribution of individuals and species in trait space, together with the relationships between functional traits and PC axes. All eight sampled species are included, colour-coded by order of height distribution (top left). Species legend: A, Pelvetia canaliculata; B, Fucus spiralis; C, Halidrys siliquosa; D, Ascophyllum nodosum; E, F. vesiculosus; F, F. serratus;

for PC2 (ANOVA; Table 2) and for all individual traits together (Table S4). However, these interactions and the main effects of site were much weaker than those of species (PC1: site $8 \%$ vs. species $72 \%$; PC2: site $2 \%$ vs. species $72 \%$ and site* species $5.5 \%$; individual traits: site $6.7 \%$ vs. species $53 \%$ and site*species $9.4 \%$ ), indicating that the
G, Saccharina latissima; and H, Laminaria digitata. Lower panels show species variation in PC scores, with species sorted by relative height $(\mathrm{RH}$, as proportion, relative to the total tidal variation; full description in "Methods"). Two species were removed from the boxplots due to their low occurrences: $H$. siliquosa and S. latissima. Contributions of each trait to the PCA axes are given in Table S2

readjustments of species' relative trait values at different sites are much smaller than the overall differences between them. Still, we can observe changes in the trait means across sites for some species, although not clearly continuous along the exposure gradient (except for $F$. vesiculosus, which increased in thickness consistently and positively with 
Table 2 Result of ANOVAs examining the effect of species and site on individuals' scores on the first two axes of the principal component analysis based on traits

\begin{tabular}{lrrrrrr}
\hline & $d f$ & Sum Sq & Mean Sq & $F$ value & $p$ value & Partial $R^{2}$ \\
\hline Axis 1- $R^{2}: 0.82$ & & & & & & \\
Site & 3 & 30.859 & 10.286 & 20.1006 & $<\mathbf{0 . 0 0 1}$ & 0.080 \\
Species & 5 & 276.483 & 55.297 & 108.0572 & $<\mathbf{0 . 0 0 1}$ & 0.716 \\
Site*species & 13 & 11.111 & 0.855 & 1.6702 & 0.074 & 0.029 \\
Residuals & 133 & 67.5 & 0.508 & & & \\
Axis 2- $R^{2}: 0.79$ & & & & & & \\
Site & 3 & 4.183 & 1.394 & 3.6491 & $<\mathbf{0 . 0 5}$ & 0.017 \\
Species & 5 & 176.168 & 35.234 & 92.2094 & $<\mathbf{0 . 0 0 1}$ & 0.719 \\
Site*species & 13 & 13.372 & 1.029 & 2.7773 & $\mathbf{0 . 0 0 1}$ & 0.055 \\
Residuals & 134 & 51.202 & 0.382 & & & \\
\hline
\end{tabular}

Degrees of freedom $(d f)$, and test statistics (sum of squared differences, mean of squared differences, $F$ value, and $p$ value) are given, as well as an estimated variance explained (partial $R^{2}$ )

Significant values are in bold

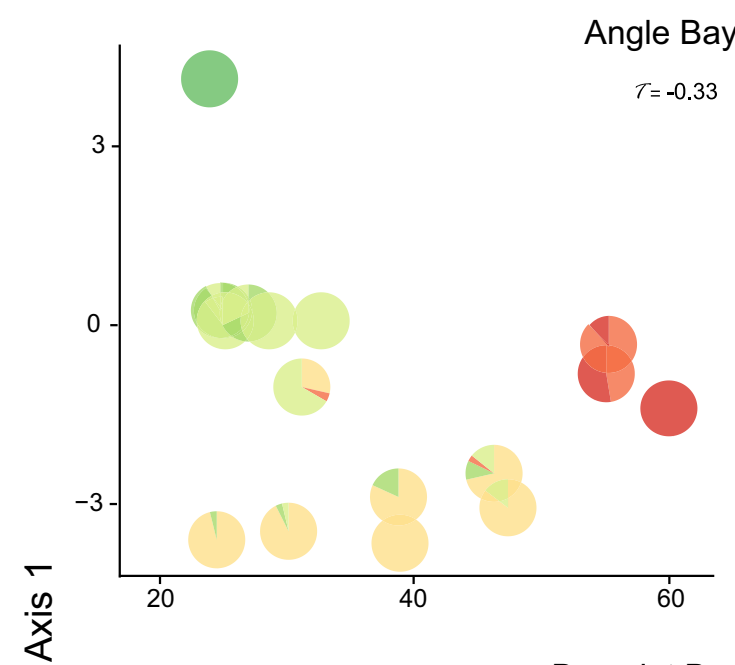

Bracelet Bay

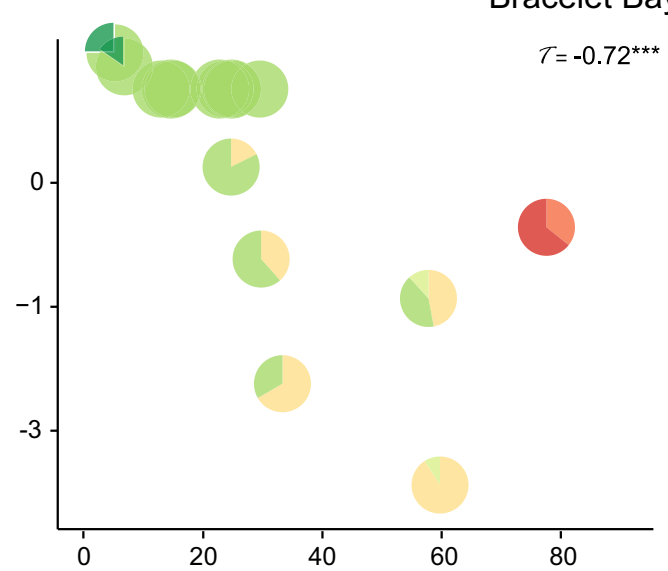

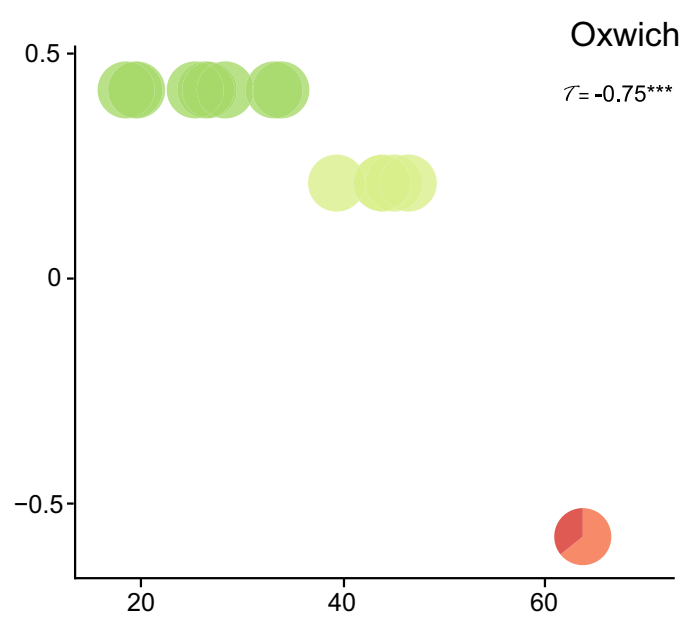

Rhossili

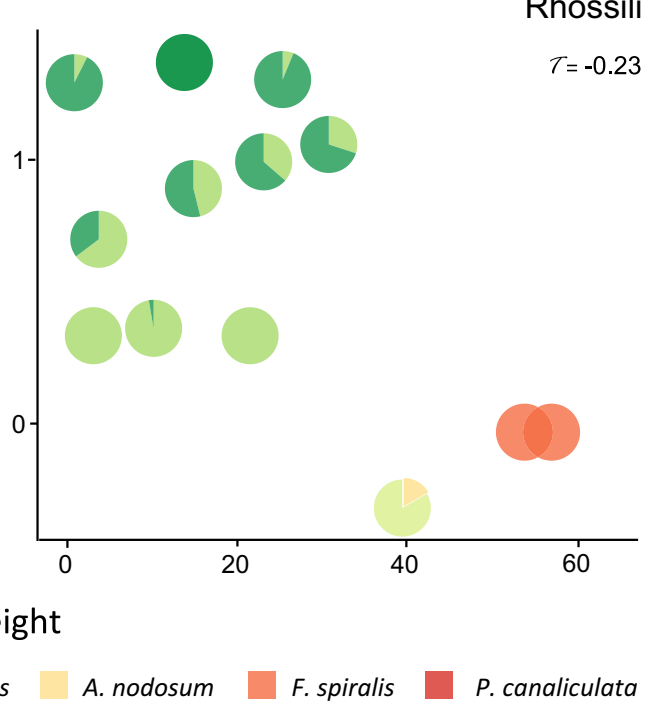

Fig. 2 Community weighted means (CWMs) of the first PCA axis along relative heights (as proportion, relative to the total tidal variation; full description in "Methods". Note that sites differ in range).
Pie charts represent species relative abundances for each point (quadrat) and Kendal's tau is given for each site, with significant values $(p<0.01)$ shown with asterisks 


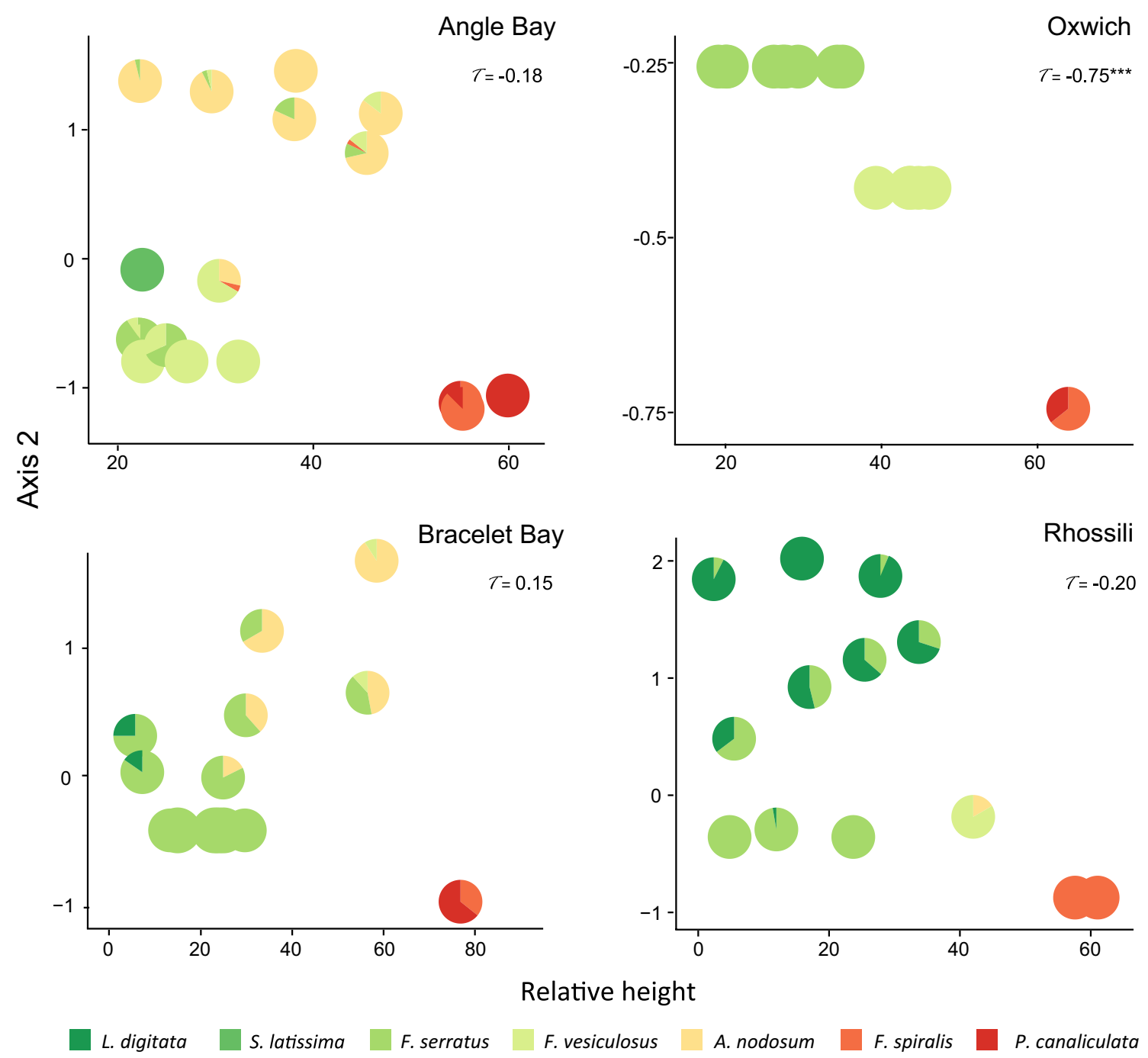

Fig. 3 Community weighted means (CWMs) of the second PCA axis along relative heights (as proportion, relative to the total tidal variation; full description in "Methods". Note that sites differ in range).

exposure; Fig. S1). Residual intraspecific variability could not be attributed to variation in the relative height of collected samples (Appendix S3, Table S3).

\section{Discussion}

Addressing trait variability at both within- and betweenspecies levels provides insights to inform the study of functional diversity in macroalgal communities (Demes and Pruitt 2019). We investigated a group of dominant macroalgae in rocky intertidal shores, the "large brown macroalgae" (LBM) to reveal the levels of morphological trait variability and how these relate to environmental gradients and ecological strategies. We, therefore, bring a new perspective to the study of macroalgal functional ecology, which has so far
Pie charts represent species relative abundances for each point (quadrat) and Kendal's tau is given for each site, with significant values $(p<0.01)$ shown with asterisks

remained largely restricted to classifying species into—and comparing-functional groups.

Trait variability among LBM was largely captured by two key axes and could be related to species' position on the shore and ecological strategies. The existence of two major axes of variation (at least based on the suite of traits measured here) is consistent with studies of vascular plants (Pescador et al. 2015; Díaz et al. 2016). The first, analogous to the 'leaf economics' axis in plants, is representative of resource acquisition vs. conservation/stress-tolerance trade-offs. That is, LBM will either have high STA and SAV, and, therefore, high productivity, or have a high TDMC and more resistance to mechanical or desiccation stress. The second axis requires more interpretation, but we argue that it relates to competitive dominance. Longer LBM have higher canopies that are competitively dominant for 
light, while a greater proportional investment in anchoring holdfasts and thicker blades provides physical resistance to the increased drag associated with larger fronds (Wernberg and Thomsen 2005). With the exception of Ascophyllum, species' positions on these axes broadly reflect their position on the shore, as we hypothesised, with species higher on the shore scoring lower on PC1 and 2. The outlying traits of the mid-shore Ascophyllum appear to reflect its unique strategy among mid-shore species: slow and persistent growth, resisting physical and biological stressors over a long lifespan (10-15 years; Sundene 1973), to eventually dominate latesuccessional assemblages at sheltered sites (Topinka et al. 1981, Vadas et al. 1990). This strategy appears to require traits that are more conservative than other mid-shore species and also shifts it higher on the second axis reflecting greater thallus thickness (especially) and length. The case of Ascophyllum suggests that the first trait dimension can relate to both stress tolerance and competitive strategy, which can blur the relationship between traits and environmental stress gradients, such as that represented by shore height.

Although we examined species' trait values in relation to their mean shore position, these species often exist in mixed assemblages. Community weighted means allow integration across species in these mixed assemblages (most strongly reflecting the dominants) and indicate consequences for ecosystem functioning ("mass-ratio hypothesis", Grime 1998). It should be noted here that, although a simplification, the use of species' level mean trait values in CWMs was validated by our analysis showing species identity as the dominant source of trait variability. At Bracelet Bay and Oxwich, both at the middle of the exposure gradient, we observed a decline in $\mathrm{CWMs}$ of $\mathrm{PC} 1$. This means that communities in the more environmentally stressful higher shore were dominated by species with a more conservative thallus structure (low STA/high TDMC). This is consistent with our expectation, with species dominating the higher shore needing to conserve resources (especially water). At Oxwich, there was also a decline in PC2, illustrating that upper shore communities invested proportionally less in holdfasts and were shorter (less competitive). The implications are a slowing of ecosystem functions such as primary productivity (Reich 2014) towards higher on the shore, potentially affecting ecosystem services by reducing the volume of material available to biomass harvesting or fisheries, as well as decreasing the potential for wave attenuation (Smale et al. 2013). Nevertheless, these higher shore communities may still provide valuable functions. For instance, they support and shade faunal assemblages where the threat of desiccation and excessive heat is most extreme. In addition, their more recalcitrant tissue should persist longer in the environment, driving longterm carbon sequestration (Chung et al. 2011).

However, at sites located at the extremes of the wave exposure gradient, there was no clear relationship between shore height and CWMs for either PCs. At the very exposed Rhossili, low-shore L. digitata appeared to benefit from the level of exposure, as well as the presence of rockpools, and expanded to almost $30 \%$ of the shore height, raising CWMs through the mid-shore. At sheltered Angle Bay, the dominance of the outlier A. nodosum in many of the quadrats throughout the mid-shore depressed $\mathrm{PC} 1$ and elevated PC2. Together, these results show that the correspondence between shore height and CWMs can be disrupted where species show diffuse zonation and shifts in vertical position, or where species possess unusual traits relative to their shore height-A. nodosum in this case.

We also aimed to compare within- to between-species variability. Among individuals of the same species, trait adjustments across sites were proportionally small (relative to interspecific variability). It was also not present for all species and traits and it did not vary in a consistent manner across the wave exposure gradient, thus indicating that either other environmental factors might be driving this intraspecific variation, or that our scale was not large enough to detect the expected influence of wave exposure (or a combination of both). Still, this intraspecific variation in traits at such a small spatial scale supports previous studies in LBM (Sjøtun and Fredriksen 1995; Blanchette 1997; Wing et al. 2007) and exemplifies the potential for these species to change their morphology to match environmental conditions, which can be attributed to both adaptive variation and phenotypic plasticity (King et al. 2017). At the interspecific level, we show that considering LBM as a single "functional group", and therefore ecologically similar, can obscure and underestimate functional diversity. Using multiple continuous functional traits, as demonstrated in this study, provides a solution by allowing individuals and species to be positioned in continuous trait space. Following efforts in terrestrial plants (Díaz et al. 2016), the functional diversity of seaweed should be resolved more generally by expanding this approach to other species of LBM worldwide through coordinated trait screening initiatives. This could shed new light on topics in seaweed ecology, such as their functional biogeography and response to global change drivers (Harley et al. 2012; Violle et al. 2014). Our finding that interspecific trait variability overwhelmed intraspecific variability in LBM supports an initial application of these traits at the species level. Nevertheless, the prevalent, albeit relatively weak, species-site interactions we found here indicate more accurate estimations of functional diversity could ultimately be gained by integrating intraspecific variation.

Our approach has some limitations associated with the scope and focus of our study. We pragmatically used indirect measurements of the gradients of wave exposure (wave fetch of different sites) and tidal emersion (relative shore height), and did not consider direct mediators of stress on individuals such as drag forces or evaporation 
potential. This is a first step towards understanding spatial variation in seaweed functional traits and is analogous, for example, to using altitude in terrestrial studies of plant functional diversity. We also chose traits as functional markers (sensu Garnier et al. 2004), which provided an efficient way to screen multiple dimensions of variability at the cost of fine-scale mechanistic insight. The addition of other traits may offer more detail in studies such as ours. For example: positive buoyancy and the presence of pneumatocysts, which can enhance competitive dominance in the water column, and phenolic compound content, which can help the persistence and dominance of resource-conservative species by granting protection against grazers (Amsler 2008). Finally, we focused on the trait rather than phylogenetic differences among species. We recognise that these differences have an evolutionary basis, such that close relatives are likely to share similar shore heights and traits (e.g., lower shore kelps with high STA vs. mid-shore fucoids with lower STA). However, in light of our a priori hypotheses linking traits to shore height, the mechanistic and ecologically important connections between species' identities, traits, and shore heights stand to be complemented—but not undermined by - an understanding of their evolutionary basis (de Bello et al. 2015).

In conclusion, we have reported the first attempt to position species of large brown macroalgae in a continuous, multidimensional, trait space. Reminiscent of findings from terrestrial plants, species were concentrated along a two-dimensional plane defined by axes of resource acquisition and competitive dominance. We found that predicting seaweed trait responses to the intertidal (stress) emersion gradient is challenging, because (1) resource conservation traits can be related to competitive as well as stress-tolerance strategies, and (2) community zonation patterns can be modified by wave exposure. Overall, our study demonstrates the potential for functional traits to reveal new dimensions of diversity among macroalgae and unify ecological methods and perspectives across ecosystems and evolutionarily divergent producer groups.

Acknowledgements We thank Andrew J. King for the contributions to the manuscript; Tom P. Fairchild for the technical help; Mike Burrows for the help obtaining the fetch data; Olga Koppel and Josh Mutter for their help in the field and the lab; Igor S. Pessi for the help with the images; and Amanda Cappelatti for the illustrations. We also thank the reviewers for their suggestions.

Author contributions LC and JG conceived the ideas and designed the methodology; LC collected and analysed the data; LC and JG led the writing of the manuscript; AM contributed throughout the development of the study and the manuscript. All authors contributed critically to the drafts and gave final approval for publication.

\section{Compliance with ethical standards}

Conflict of interest All authors declare that they have no conflict of interest and that all applicable guidelines for sampling of organisms have been followed. This research has been funded by the Brazilian National Council for Scientific and Technological Development (CNPq-Science Without Borders Grant 202032/2015-9).

Open Access This article is distributed under the terms of the Creative Commons Attribution 4.0 International License (http://creativeco mmons.org/licenses/by/4.0/), which permits unrestricted use, distribution, and reproduction in any medium, provided you give appropriate credit to the original author(s) and the source, provide a link to the Creative Commons license, and indicate if changes were made.

\section{References}

Amsler CD (2008) Algal chemical ecology. Springer, Berlin Aquilino K, Bracken M, Faubel M, Stachowicz J (2009) Local-scale nutrient regeneration facilitates seaweed growth on waveexposed rocky shores in an upwelling system. Limnol Oceanogr 54(1):309-317

Arenas F, Sánchez I, Hawkins SJ, Jenkins SR (2016) The invasibility of marine algal assemblages: role of functional diversity and identity. Ecology 87(11):2851-2861

Bäck S (1993) Morphological variation of northern Baltic Fucus vesiculosus along the exposure gradient. Annales Botanici Fennici 30:275-283

Ballantine WJ (1961) A biologically-defined exposure scale for the comparative description of rocky shores. Field Studies Council, p 19

Bates D, Maechler M, Bolker B, Walker S (2015) Fitting linear mixedeffects models using lme4. J Stat Softw 67(1):1-48. https://doi. org/10.18637/jss.v067.i01

Bivand R, Keitt T, Rowlingson B (2018) rgdal: Bindings for the 'Geospatial' Data Abstraction Library. R package version 1.2-18

Blanchette CA (1997) Size and survival of intertidal plants in response to wave action: a case study with Fucus gardneri. Ecology 78(5):1563-1578. https://doi.org/10.2307/2266149

Bloomfield KJ, Cernusak LA, Eamus D et al (2018) A continentalscale assessment of variability in leaf traits: within species, across sites and between seasons. Funct Ecol 32:1492-1506. https://doi. org/10.1111/1365-2435.13097

Burrows MT (2012) Influences of wave fetch, tidal flow and ocean colour on subtidal rocky communities. Mar Ecol Prog Ser 445:193207. https://doi.org/10.3354/meps09422

Burrows MT, Harvey R, Robb L (2008) Wave exposure indices from digital coastlines and the prediction of rocky shore community structure. Mar Ecol Prog Ser 353:1-12. https://doi.org/10.3354/ meps07284

Chapman ARO (1995) Functional ecology of fucoid algae: twentythree years of progress. Phycologia 34(1):1-32. https://doi. org/10.2216/i0031-8884-34-1-1.1

Chung IK, Beardall J, Mehta S, Sahoo D, Stojkovic S (2011) Using marine macroalgae for carbon sequestration: a critical appraisal. J Appl Phycol 23:877-886. https://doi.org/10.1007/s1081 1-010-9604-9

Cornelissen JHC, Lavorel S, Garnier E et al (2003) Handbook of protocols for standardised and easy measurement of plant functional traits worldwide. Australian J Botany 51(4):335-380. https://doi. org/10.1071/BT02124 
Cornwell WK, Ackerly DD (2009) Community assembly and shifts in plant trait distributions across an environmental gradient in coastal California. Ecol Monographs 79(1):109-126. https://doi. org/10.1890/07-1134.1

Cousens R (1982) The effect of exposure to wave action on the morphology and pigmentation of Ascophyllum nodosum (L.) Le Jolis in South-Eastern Canada. Bot Mar 25:191-195

Dayton PK (1985) Ecology of kelp communities. Ann Rev Ecol Syst $16: 215-245$

de Bello F, Berg M, Dias A, Diniz-Filho J et al (2015) On the need for phylogenetic 'corrections' in functional trait-based approaches. Fol Geobot 50:3. https://doi.org/10.1007/s1222 4-015-9228-6

Demes KW, Pruitt JN (2019) Individuality in seaweeds and why we need to care. J Phycol 55(2):247-256. https://doi.org/10.1111/ jpy. 12845

Dethier MN, Graham ES, Cohen S, Tear M (1993) Visual versus random-point percent cover estimations: 'objective' is not always better. Mar Ecol Prog Ser 96:93-100

Díaz S, Hodgson JG, Thompson K et al (2004) The plant traits that drive ecosystems: evidence from three continents. J Veg Sci 15(3):295-304. https://doi.org/10.1111/j.1654-1103.2004.tb022 66. $\mathrm{x}$

Díaz S, Kattge J, Cornelissen J et al (2016) The global spectrum of plant form and function. Nature 529:167-177. https://doi. org/10.1038/nature 16489

Dray S, Dufour AB (2007) The ade4 package: implementing the duality diagram for ecologists. J Stat Softw 22:1-20

Edmunds E, Carpenter R (2001) Recovery of Diadema antillarum reduces macroalgal cover and increases abundance of juvenile corals on a Caribbean reef. PNAS 98(9):5067-5071

Fajardo A, Piper F (2011) Intraspecific trait variation and covariation in a widespread tree species (Nothofagus pumilio) in southern Chile. New Phytol 189:259-271. https://doi.org/10.111 $1 /$ j.1469-8137.2010.03468.x

Garnier E, Cortez J, Billè G et al (2004) Plant functional markers capture ecosystem properties during secondary succession. Ecology 85(9):2630-2637. https://doi.org/10.1890/03-0799

Gómez I, Huovinen P (2011) Morpho-functional patterns and zonation of south Chilean seaweeds: the importance of photosynthetic and bio-optical traits. Mar Ecol Prog Ser 422:7791. https://doi. org/10.3354/meps08937

Grime JP (1974) Vegetation classification by reference to strategies. Nature 250:31-36. https://doi.org/10.1038/250026a0

Grime JP (1998) Benefits of plant diversity to ecosystems: immediate, filter and founder effects. J Ecol 86:902-910

Harley CDG, Anderson KM, Demes KW et al (2012) Effects of climate change on global seaweed communities. J Phycol 48:1064-1078

Hein M, Pedersen MF, Sand-Jensen K (1995) Size-dependent nitrogen uptake in micro- and macroalgae. Mar Ecol Prog Ser 118:247-253

Hepburn CD, Holborow JD, Wing SR, Frew RD, Hurd CL (2007) Exposure to waves enhances the growth rate and nitrogen status of the giant kelp Macrocystis pyrifera. Mar Ecol Prog Ser 339:99-108. https://doi.org/10.3354/meps339099

Hodgson JG, Wilson PJ, Hunt R, Grime JP, Thompson K (1999) Allocating C-S-R plant functional types: a soft approach to a hard problem. Oikos 85:282-296

Hurd C, Harrison P, Bischof K, Lobban C (2014) Seaweed ecology and physiology. Cambridge University Press, Cambridge. https://doi. org/10.1017/CBO9781139192637

King NG, McKeown NJ, Smale DA, Moore PJ (2017) The importance of phenotypic plasticity and local adaptation in driving intraspecific variability in thermal niches of marine macrophytes. Ecography 40:001-014. https://doi.org/10.1111/ecog.03186

Kraft NJB, Cornwell WK, Webb CO, Ackerly DD (2007) Trait evolution, community assembly, and the phylogenetic structure of ecological communities. Am Nat 170(2):271-283. https://doi. org/10.1086/519400

Laliberté E, Legendre P, Shipley B (2014) FD: measuring functional diversity from multiple traits, and other tools for functional ecology. R package version 1.0-12

Littler MM (1980) Morphological form and photosynthetic performances of marine macroalgae: tests of a functional/form hypothesis. Bot Mar 23:161-165. https://doi.org/10.1515/ botm.1980.23.3.161

Littler MM, Littler DS (1980) The evolution of thallus form and survival strategies in benthic marine macroalgae: field and laboratory tests of a functional form model. Am Nat 116(1):25-44. https:// doi.org/10.1086/283610

Markager S, Sand-Jensen K (1996) Implications of thallus thickness for growth-irradiance relationships of marine macroalgae. Eur J Phycol 31(1):79-87. https://doi.org/10.1080/09670269600651231

Mokany K, Ash J, Roxburgh S (2008) Functional identity is more important than diversity in influencing ecosystem processes in a temperate native grassland. J Ecol 96(5):884-893. https://doi.org /10.1111/j.1365-2745.2008.01395.x

Oksanen J, Blanchet F, Friendly M, Kindt R et al (2018) vegan: Community Ecology Package. R package version 2.4-6

Pescador D, de Bello F, Valladares F, Escudero A (2015) Plant trait variation along an altitudinal gradient in mediterranean high mountain grasslands: controlling the species turnover effect. PLoS One 10(3):1-16. https://doi.org/10.1371/journal.pone.0118876

R Core Team (2018) R: a language and environment for statistical computing. R Foundation for Statistical Computing, Vienna, Austria. https://www.R-project.org/

Reich PB (2014) The world-wide "fast-slow" plant economics spectrum: a traits manifesto. J Ecol 102(2):275-301. https://doi. org/10.1111/1365-2745.12211

Reich PB, Ellsworth DS, Walters MB et al (1999) Generality of leaf trait relationships: a test across six biomes. Ecology 80(6):1955-1969

Rodriguez S, Martín AP, Sousa-Pinto I, Arenas F (2016) Biodiversity effects on macroalgal productivity: exploring the roles of richness, evenness and species traits. Mar Ecol Prog Ser 562:79-91. https ://doi.org/10.3354/meps11948

Sakanishi Y, Kasai H, Enomoto K, Toda M, Tanaka J (2017) Productivity and thallus toughness trade-off relationship in marine macroalgae from the Japan Sea. Phycol Res 65(2):103-110. https ://doi.org/10.1111/pre.12168

Schneider CA, Rasband WS, Eliceiri KW (2012) NIH Image to ImageJ: 25 years of image analysis. Nat Methods 9(7):671-675

Schonbeck M, Norton TA (1979) Drought-hardening in the uppershore seaweeds Fucus spiralis and Pelvetia canaliculata. J Ecol 67(2):687-696

Seers B (2017) fetchR: calculate wind fetch. R package version 2.1-0. https://CRAN.R-project.org/package $=$ fetchR

Siefert A, Violle C, Chalmandrier L et al (2015) A global meta-analysis of the relative extent of intraspecific trait variation in plant communities. Ecol Lett 18:1406-1419. https://doi.org/10.1111/ ele. 12508

Sjøtun K, Fredriksen S (1995) Growth allocation in Laminaria hyperborea (Laminariales, Phaeophyceae) in relation to age and wave exposure. Mar Ecol Prog Ser 126:213-222

Smale DA, Burrows MT, Moore P, O’Connor N, Hawkins SJ (2013) Threats and knowledge gaps for ecosystem services provided by kelp forests: a northeast Atlantic perspective. Ecol Evol 3(11):4016-4038. https://doi.org/10.1002/ece3.774

Southward AJ (1959) The zonation of plants and animals on rocky sea shores. Biol Rev 33:137-177

Steneck RS, Dethier MN (1994) A functional group approach to the structure of algal-dominated communities. Oikos 69:476-498 
Suding KN, Lavorel S, Chapin FS et al (2008) Scaling environmental change through the community-level: a trait-based response-andeffect framework for plants. Glob Change Biol 14(5):1125-1140. https://doi.org/10.1111/j.1365-2486.2008.01557.x

Sundene O (1973) Growth and reproduction in Ascophyllum nodosum (Phaeophyceae). Norwegian J Botany 20:249-255

Topinka J, Tucker L, Korjeff W (1981) The distribution of fucoid macroalgal biomass along central coastal maine. Bot Mar 24(6):311320. https://doi.org/10.1515/botm.1981.24.6.311

Vadas RL, Wright WA, Miller SL (1990) Recruitment of Ascophyllum nodosum: wave action as a source of mortality. Mar Ecol Prog Ser 61:263-272

van Buuren S, Groothuis-Oudshoorn K (2011) mice: multivariate Imputation by Chained Equations in R. J Stat Softw 45(3):1-67

Vile D, Shipley B, Garnier E (2006) Ecosystem productivity can be predicted from potential relative growth rate and species abundance. Ecol Lett 9:1061-1067. https://doi.org/10.111 1/j.1461-0248.2006.00958.x

Violle C, Reich PB, Pacala SW, Enquist BJ, Kattge J (2014) The Emergence and promise of functional biogeography. PNAS 111(38):13690-13696. https://doi.org/10.1073/pnas.1415442111
Wernberg T, Thomsen MS (2005) The effect of wave exposure on the morphology of Ecklonia radiata. Aquat Bot 83:61-70

Wilson PJ, Thompson K, Hodgson JG (1999) Specific leaf area and leaf dry matter content as alternative predictors of plant strategies. New Phytol 143:155-162. https://doi.org/10.104 6/j.1469-8137.1999.00427.x

Wing SR, Leichter JJ, Perrin C, Rutger SM, Bowman MH, Cornelisen CD (2007) Topographic shading and wave exposure influence morphology and ecophysiology of Ecklonia radiata (C. Agardh 1817) in Fiordland, New Zealand. Limnol Oceanogr 52(5):18531864. https://doi.org/10.4319/lo.2007.52.5.1853

Publisher's Note Springer Nature remains neutral with regard to jurisdictional claims in published maps and institutional affiliations. 